\title{
Gendered perceptions of tigers in Chitwan National Park, Nepal
}

Neil H. Carter ${ }^{a}$ and Teri D. Allendorf ${ }^{b}$

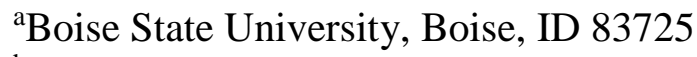

bUniversity of Wisconsin-Madison, Madison, WI 53706, USA

Corresponding author: Teri D. Allendorf, allendorf@wisc.edu, 608-262-3946

(C) 2016. This manuscript version is made available under the Elsevier user license http://www.elsevier.com/open-access/userlicense/1.0/ 


\begin{abstract}
The survival of many populations of threatened mammals depends on the willingness of human communities to coexist with them. Gender is an important factor because men and women often have different perceptions of wildlife that influence their willingness to coexist with wildlife. While previous studies have hypothesized what may drive gendered perceptions of wildlife, research investigating the underlying drivers of these differences is lacking, especially in developing countries. The objective of this paper is to identify the underlying drivers of gendered differences in attitude toward globally endangered tigers (Panthera tigris) in Chitwan National Park (CNP), Nepal, where women are less likely to have a positive attitude. To accomplish this, we administered a social survey to 499 respondents living near the Park. We analyzed survey data using nested linear regression models and decomposition analysis. Over $90 \%$ of the gender gap in attitude was explained through these analyses, with beliefs about tigers (e.g., benefits and costs) explaining two-thirds of the gap. The belief that tigers contribute to a healthy ecosystem, by itself, accounted for one-third of the gender gap. Socioeconomic characteristics explained $12 \%$ and experiences with tigers and perceptions of and control over risk each accounted for $6 \%$ or less of the gender gap. These results suggest that beliefs, rather than socioeconomics, experience, or risk, underlie the majority of the gendered differences in attitudes toward tigers in CNP and that an appreciation of the ecosystem value of tigers plays a key role in people's positive attitudes. Analyses of gendered differences in attitudes is important for developing conservation interventions that address perspectives and issues of the entire population.
\end{abstract}

Key words: attitudes; perceptions; wildlife; tiger; gender; Nepal 


\section{Introduction}

From grassroots conservation projects to international committees, women are underrepresented in biodiversity conservation processes (Deda and Rubian 2004; Sodhi et al. 2010). The lack of women's representation contributes to socially unjust conservation (Ogra 2008), inequitablydistributed costs and benefits of conservation (Martino 2008), and less effective conservation efforts (Agarwal 2000). A gender-sensitive approach to conservation contributes to more fair and inclusive processes and to more effective conservation (Sodhi et al. 2010). Natural resource management groups that include women demonstrate greater collaboration, solidarity, and conflict resolution characteristics than those with only men (Westermann et al. 2005). In turn, those characteristics contribute to better outcomes: women's participation in forestry groups in India and Nepal is correlated with better overall condition and faster regeneration due to better monitoring and better rule enforcement (Agarwal 2009).

The consideration of gendered perspectives in natural resource management is relatively new but has yielded valuable insights with tangible impacts on natural resource use and management, such as the role that women play in the management of natural resources and the difficulty of implementing programs without their support (Arora-Jonsson 2014). For example, in contrast to the traditional male-dominated timber-orientation in forest management, gendered perspectives helped to reveal the importance of non-timber forest products for household livelihoods (Colfer 2013). Wildlife conservation is similarly dominated by male perspectives and the inclusion of a gendered perspective may lead to new insights into wildlife conservation and ways that humans and wildlife can co-exist (Hunter et al. 1990; Carter \& Linnell 2016).

Women and men often have different perceptions of wildlife. In general, women show more concern for wildlife (Kellert \& Berry 1987) and are generally more supportive of species conservation (Czech et al. 2001) and of treating species humanely (Dougherty et al. 2003). Additionally, although women may perceive higher risks from wildlife, they are less willing to accept destroying them (Zinn \& Pierce 2002). Women's more positive perceptions toward wildlife are thought to be based on women's greater moral and ethical emphasis on relationships and their caretaking and nurturing characteristics, compared to men's relative emphasis on competition and autonomy (Kellert and Berry, 1987).

However, in contexts where negative impacts of wildlife can be a daily occurrence through crop raiding and livestock depredation, women are often more negative than men (Gillingham and Lee, 1999; Gore and Kahler, 2012; Kaltenborn et al., 2006; Suryawanshi et al., 2014), although not always (Arjunan et al. 2006; Yang et al. 2010). In these contexts, gendered attitude differences are hypothesized to be caused by greater direct costs of wildlife to women, women's greater fear of wildlife and greater perceptions of risk, and women's lack of information and knowledge about conservation and wildlife. Gendered divisions of labor can disproportionally expose women and their economic activities to risks from wildlife. Woman are often primarily responsible for the collection of many natural resources, such as fuelwood and fodder, for the household, which can expose them to attack from wildlife while collecting (Ogra 2008), and they can also be primarily responsible for many agricultural activities, which may expose them to the risks of wildlife eating crops or killing livestock (Hunter et al. 1990). It is also possible that women's more negative attitudes may be driven by their greater fears and perceptions of risk from wildlife. In general, woman are universally more afraid than men (Fredrikson et al. 1996) 
and have higher levels of concern about risks than men (Gustafsod 1998), and these generalities seem to hold true for wildlife (Gore and Kahler, 2012; Hill, 1998; Kaltenborn et al., 2006). Other reasons for women's more negative attitudes include their marginalized positions in society and the fact that their primary responsibilities in the domestic sphere limit their ability to participate in activities outside the home, such as community meetings, which would give them access to information about conservation and wildlife (Allendorf and Yang, 2015; Gillingham and Lee, 1999; Hill, 1998).

Unfortunately, research investigating the underlying drivers of gendered differences in attitude toward wildlife is lacking. Understanding the drivers of differences in how men and women value and perceive wildlife is important because perceptions tend to correlate with how people behave toward wildlife, including their support for wildlife conservation (Bruskotter \& Wilson 2014). Evaluating gendered attitudes can provide insights on developing more effective interventions that account for the role of gender. This is particularly important as men's and women's roles in society, and the values underpinning those roles, are undergoing changes throughout much of the developing world (Dorius and Firebaugh, 2010; Grant and Behrman, 2010). Furthermore, knowledge about gendered attitudes will shed crucial light on factors shaping human judgments toward wildlife and the environment more broadly, which can be useful for decision makers seeking to address the priorities of a broad range of stakeholders (Carter et al. 2014b).

The objective of this paper is to identify the underlying drivers of gendered differences in attitude toward tigers in Chitwan National Park (CNP), Nepal. A previous study found that women are more negative toward tigers than men in this area (Carter et al., 2014a). However, in this paper, we go further than previous studies by exploring the drivers of this gender gap. The drivers we consider include socioeconomic characteristics, experience with tigers, perceptions of risks from tigers, perceptions of control over risk from tigers, and beliefs about tigers. We chose these potential drivers based on previous research on human attitudes toward wildlife (Carter et al., 2012a; Kansky et al. 2014) and based on social-psychological theories of how human judgements toward wildlife are formed (Bruskotter \& Wilson 2014).

\section{Study area}

Nepal's CNP was established in 1973 and is currently about $1,000 \mathrm{~km}^{2}$. The park is located in a river valley basin along the flood plains of the Rapti, Rue, and Narayani Rivers at altitudes from 150 to $815 \mathrm{~m}$ (Figure 1). The park experiences a subtropical climate, with a cool dry winter and a summer monsoon from mid-June to late September (Laurie 1982).

As in many developing regions (Bearer et al. 2008), most people in the area depend on crops and livestock for their livelihood, and rely on forest products (e.g., livestock fodder, fuelwood) to support their agriculture-dependent livelihoods (Sharma 1990). However, relatively easy access to roads and markets contribute to nonfarm job opportunities in Chitwan. The nonfarm sector is the highest share of total household income in the central region of Nepal, which includes Chitwan, compared to other regions (CBS, 2012). Furthermore, the lure of employment in urban areas where higher-paying jobs are more prevalent, has spurred out-migration. Those migrating from Chitwan are mostly men, leaving the women to maintain the households and collect forest resources (Bohra and Massey, 2009; Chen et al., 2012). An increasing proportion of household 
income comes from remittances sent from family members working in areas outside Chitwan (Bohra and Massey, 2009; Chen et al., 2012). These remittances are important sources of income as Nepal is classified as a low-income country ( $<$ US $\$ 1,005$ per capita annual income) according to the World Bank.

[Figure 1 about here]

In general, people living near the park are restricted from entering in order to collect forest products (Carter et al., 2012b). However, a 'grass-cutting' program was initiated in 1976 to allow local residents to enter the park for approximately two weeks annually to collect thatch grass, reeds, rope bark, and rope grass (but not wood) (Stræde and Helles 2000). A buffer zone ( 750

$\mathrm{km}^{2}$ ) surrounding the park was established in 1996. Approximately 30-50\% of park revenue from visitor entry fees is used each year to support various community development projects and forest protection programs (e.g., community forests) in the buffer zone (Government of Nepal 1993). Community development projects have focused on enhancing the livelihoods of indigenous people, low-income groups, and women. For example, local people have received training needed to shift from traditional subsistence farming to cash crops and operate smallscale off-farm tourism businesses (Nyaupane and Poudel, 2011). Building the capacity of local people to market and provide service to tourists is important, because tourist numbers in Chitwan have more than tripled between 1990 (36,500) and 2009 (113,788) (Bookbinder et al. 1998, Government of Nepal 2009). In addition, management responsibility for several forest tracts in the buffer zone was devolved to local community user groups (Nagendra et al. 2005, Gurung et al. 2008). Decisions on when and how natural resources can be collected from those community forests now reside with local residents according to state-sanctioned management plans (Nagendra et al. 2005).

Despite a relatively large human population living near the park $(\sim 300,000$, UNEP/WCMC 2011), it is one of the success stories in tiger conservation. The tiger population in CNP has increased from approximately 50 in 1998 to 125 in 2015 (Smith et al. 1998; Karki et al. 2015). It is one of only 28 reserves in the world that can support at least 25 breeding female tigers (Wikramanayake et al. 2011). However, tigers occasionally prey on livestock and attacks on people inside and outside the park are a growing concern: sixty-five local people were killed from 1998-2006 compared to 6 from 1989-1997 (Gurung et al. 2008). A government program exists to compensate losses from tigers, with a mean payment of $\$ 1,900$ (2007 - 2014) given to families of people killed by tigers and payments for depredated livestock averaging $50 \%$ of their monetary value (Dhungana et al., 2016). Although illegal killing of tigers, especially for economic gain (e.g., selling body parts in illicit markets), is a persistent threat in Nepal and elsewhere, it has been significantly reduced in Nepal over the last few years (Nowell, 2012).

\section{Methods}

\subsection{Data collection}

In December 2009 we pre-tested the survey $(n=17)$ in a site adjacent to our study area (Fig. 1), to ensure internal validity of our survey measures. We then randomly selected 500 residences within wards (the smallest administrative unit in Nepal) in the study area that were directly adjacent to the National Park or adjoining buffer zone. The spatial location of each residence was obtained from a Geographic Information System compiled by the Nepal Government in 1996. 
These georeferenced data are the best available in the region; however, the number of residences has increased since 1996.

In February 2010, the name and age of all individuals living in each of the 500 residences were recorded and compiled in a list. Inclusion criterion was that they must have been residing in the house during the week prior to the time when the survey would be administered. From this list, a single individual between the ages of 15 and 59 was randomly selected for survey from each of the 500 randomly selected residences. This resulted in a total of 500 possible respondents. From March - April 2010, trained local interviewers contacted each possible respondent to conduct the survey face-to-face. A verbal consent script was read to the subjects, because many adult subjects were not literate. After the subjects gave their verbal consent, interviews and collection of respondent's exact household location with a hand-held Global Positioning System unit proceeded. No further information was to be recorded in case the subject did not consent. The study, including the verbal consent process and script, was reviewed and approved by the Institutional Review Board (IRB\# 08-274) of Michigan State University.

\subsection{Survey Measures}

In examining the determinants of attitudes toward tigers in CNP, we focused on five categories of variables: socio-economic characteristics, experience with tiger, perceptions of risk from tiger, perceptions of control over the risk, and beliefs about tiger.

\section{[Table 1 about here]}

Socio-economic characteristics include age, occupation, education, caste/ethnicity, and residency length. All of these characteristics have been shown to relate with attitudes toward wildlife. Age categories are less than 30 years, 30 to 39 years, 40 to 49 years, and more than 49 years.

Occupation consists of two categories, farmer or other, which includes people who own business, work for the government, or are students, for example. Education is divided into three categories: one to three years of schooling, four to seven years, eight to eleven years, and eleven or more years of schooling. Caste/ethnicity includes four categories: 1) Chetri or Bahun, 2) indigenous hill groups, 3) Dalit, and 4) indigenous terai groups. Indigenous hill group includes members of ethnic groups indigenous to the Himalayan foothills, including Tamang, Magar, and others. The indigenous terai groups include Tharus and members of other groups that are indigenous to the terai, the narrow strip of flat land that runs along the southern border of Nepal. Residency categories include being a native, one to fourteen years, 15 to 29 years, and more than 29 years.

People's experience with tigers was measured by whether or not the respondent had seen tiger sign (scat or pugmarks) and if they had ever seen tigers in the wild. Other measures of experience with tigers that were collected did not differ between men and women and so were not used in this analysis. These measures were knowledge of tiger events that had occurred, such as livestock killing (their own or others). It makes sense that this variable did not have gender differences since men and women would have equal knowledge about their own and probably a neighbor's livestock. The effect of these measures of experience on the attitudes toward tigers of all respondents is discussed in Carter et al. (2012a; 2014a). 
People's perceptions of risk from tigers were measured in terms of their worry about attacks (affective risk) from tigers and their perception of the likelihood (or cognitive risk) that an attack will occur. We distinguish these two forms of perceived risk because they have been found to diverge significantly from one another and have distinct implications on conservation actions (Carter et al., 2012a). For example, actions that reduce livestock depredations by tigers may reduce the perceived likelihood of attack but have no effect on worry about those attacks; yet, worry or fear has a strong influence on human behavior (Riley and Decker, 2000). Items measuring respondent worry about attacks from tigers and their perception of the likelihood of these attacks were highly consistent with each other. Thus, we used a scaled measure of how much they worry about their farm animals, other people in the village, or themselves or someone in their family being attacked by a tiger. A similar measure was created for their perception of the likelihood of an attack on their livestock, a person in the village, or themselves or their family. The scales were calculated using factor analysis with maximum likelihood estimation and the internal reliability of the items used in each scale were assessed using Cronbach's alpha reliability test.

Locus of control refers to whether respondents perceive events as a consequence of their own actions (under personal control) or as a consequence of powerful external agents (government control) (Bjerke et al., 2000). People's perceptions of control over risk were therefore measured with two yes/no questions: are risks from tigers avoidable and do government officials understand the risks from tigers? A third question, are risks from tigers being satisfactorily addressed by the government, did not differ between genders and was not used in the analysis.

Beliefs about tigers were measured by seven yes/no questions that captured a variety of values about tigers, two negative (nuisance and incompatibility) and five positive (religious, tourism, healthy ecosystem, cultural, and existence): 1) Do you agree that tigers are a nuisance and should be kept out of the nearby forests at all costs? 2) Do you agree that there is not enough room for both tigers and humans to live in Chitwan so tigers should leave the nearby forests? 3) Do you agree that tigers have religious values and humans should respect them by not disturbing them in the nearby forests? 4) Do you agree that your village will benefit from more tourism if tigers are in the nearby forests? 5) Do you agree that tigers should stay in the nearby forests because they keep the forests healthy? 6) Do you agree that tigers are an important part of your culture and should continue roaming the nearby forests? 7) Do you agree that tigers were in Chitwan before humans and have the right to live in the nearby forests alongside humans? The responses to the question concerning the religious values of tigers did not differ between genders and was therefore not used in the analysis.

Recent work indicates that multi-item variables (i.e., combining several survey items into one variable) better measure human attitudes toward wildlife than single-item variables (Hogberg et al. 2015). Thus, we used a three-item scaled measure of attitude toward tigers based on three questions: 1) Are you pleased that tigers exist in the forest; 2) do you enjoy having tigers in the area; and 3) would you be happy if no tigers existed in the nearby forests?

\subsection{Analysis}

The analysis takes three main steps. First, we examine the distribution by gender of attitude toward tigers and the potential determinants of attitude toward tigers. Second, we use nested 
linear regression models to examine if gender differences in the distribution of the variables explain any gendered difference in attitude. We begin with a bivariate model with gender as the only variable in the model. This bivariate model provides a baseline of the gendered difference in attitude that does not control for gendered differences in the distribution of any other variables. In a second model, we add socio-economic characteristics to see how much of the gendered difference in attitude toward tigers is explained by socio-economic characteristics alone. In a third model, we add experience with tigers to the baseline bivariate model to see how much experience alone accounts for the gender gap in attitude. In models 4-6, we add the other groups of variables - perceptions of risk, perceptions of risk control, and beliefs about tigers - to the bivariate model. In the final model, we add all the variables to see their combined contribution to explaining the gender gap in attitude.

Finally, we perform a decomposition analysis of the final full model to get a more precise estimate of the proportion of the gender gap in attitude that is explained by the model. The decomposition also provides an estimate of the contribution of each individual variable in explaining the gender gap. This allows us to know which variables are most important.

We employed the standard Blinder-Oaxaca decomposition (Blinder 1973; Oaxaca 1973), which uses a linear model (Jann 2008). The mean attitude difference to be explained $(\Delta \bar{Y})$ is the difference of the mean attitudes for men $\left(\bar{Y}_{M}\right)$ and women $\left(\bar{Y}_{W}\right)$. The mean attitudes for each group can be expressed as $\bar{Y}=\bar{X}^{\prime} \hat{\beta}$, where $\bar{X}$ contains the mean values of independent variables and $\hat{\beta}$ are the estimated regression coefficients. Hence, $\Delta \bar{Y}$ can be rewritten as:

$$
\Delta \bar{Y}=\bar{X}_{M}^{\prime} \bar{\beta}_{M}-\bar{X}_{W}^{\prime} \bar{\beta}_{W}
$$

Decomposing this equation with respect to a vector of reference coefficients $\left(\hat{\beta}_{R}\right)$ gives us:

$$
\Delta \bar{Y}=\left(\bar{X}_{M}-\bar{X}_{W}\right)^{\prime} \hat{\beta}_{R}+\bar{X}_{M}^{\prime}\left(\hat{\beta}_{M}-\hat{\beta}_{R}\right)+\bar{X}_{W}^{\prime}\left(\hat{\beta}_{R}-\hat{\beta}_{W}\right)
$$

This expression divides the difference in mean attitudes into a portion (the first term) that is explained by cross-group differences in the independent variables, and a portion (the last two terms) that remains unexplained by these differences. The first term can again be further decomposed into the contribution of each independent variable in explaining the gap in predicted attitudes between women and men. We ran the decomposition using reference coefficients from a pooled regression as suggested by Neumark (1988). Bootstrapped standard errors for each of the decomposition estimates are calculated using 1,000 sampling replicates.

\section{Results}

\subsection{Socio-economic and demographic characteristics}

Average age of respondents was 33.7 (15-59) years, more than 70\% were farmers, and nearly $63 \%$ were female. Respondents were predominantly female since many men leave Chitwan to work in urban centers in Nepal or other countries. The majority of respondents were higher caste Hindu (57\%). Respondents also had a range of education levels: $36 \%$ of respondents had less than four years of formal education, whereas $11 \%$ had at least 12 years of formal education.

\subsection{Do attitudes and possible determinants of attitude differ by gender?}

Significant gender differences existed in people's attitude toward tigers and in the five categories of variables we examined as possible determinants of attitude toward tiger: socio-economic 
characteristics, experience with tiger, perceptions of risk, perceptions of control over risk, and beliefs about tigers (Table 1).

The measurement of items concerning attitudes toward tigers showed high consistency (Cronbach's alpha $=0.82$ ). While overall the majority of people, men and women, had a positive attitude toward tigers, women were significantly less positive toward tigers than men (Table 1). Women were less likely to be pleased tigers existed in the forest and to enjoy having tigers in the area. They were more likely than men to say they would be happy if no tigers existed in the nearby forest.

The distributions of each of the socio-economic characteristics, except for age and ethnicity, also differed significantly by gender (Table 1). Women had less education than men and were more likely to give their occupation as farmer. They were less likely to be native to the area because of a marriage system where wives move to the husband's home.

Women had fewer experiences with tiger. While the majority of women and men had seen tiger sign (i.e., pugmark or scat), fewer women had seen it. Only about one-third of women had seen a tiger in the wild in comparison to over half the men.

The measurement of items for worry about risks from tigers (Cronbach's alpha $=0.90$ ) and likelihood of risks from tigers (Cronbach's alpha $=0.89$ ) showed high consistency. Women were more likely than men to be worried that tigers would attack their livestock, someone in the village, and themselves or someone in their family. Women also perceived the likelihood of attack from tigers to be higher than men. Women were less likely than men to perceive that risks from tigers are avoidable than men and they were more likely to think that the government understood the risks than men. However, women were not significantly different from men in perceiving that the government was satisfactorily addressing the risks.

In terms of beliefs about tigers, women differed significantly from men in their beliefs about tigers except for the belief that tigers have religious value. Women were more likely than men to perceive that tigers are a nuisance and that there is not enough room for tigers and humans to live together. Women were less likely than men to believe that their village will benefit from tourism if there are tigers in the forest, that tigers should be in the forest because they contribute to healthy forests, that they are an important part of culture, and that tigers have a right to live with humans.

\subsection{Do differences in socio-economics, experience with tiger, perceptions of risk, perceptions of risk control, and beliefs about tigers account for the gendered difference in attitude?}

Next, using nested linear regression models, we examine if gender differences in the distribution of the independent variables explain the gender gap in attitude toward tiger. Given high response consistency, scaled measures for worry about risks from tigers, likelihood of risks from tigers, and attitudes toward tigers were used in the models. The scaled measure for worry about risks from tigers ranged from -2.52 (less worried) to 2.13 (more worried). The scaled measure for perceived likelihood of risks from tigers ranged from -3.5 (lower likelihood) to 1.81 (higher likelihood). The scaled measure for attitudes toward tigers ranged from -1.63 (more negative attitudes) to 0.68 (more positive attitudes). All three scaled measures had a mean score of 0 . 
Results of the regression models are presented in Table 2. In model 1, the baseline model, gender has a coefficient of -.45 , indicating that women are significantly more negative toward tigers than men. In model 2, we add the socio-economic characteristics to the model and the gender coefficient decreases to -0.30 . This movement in the coefficient indicates that differences in the distribution of the socio-economic variables account for some of the gap between men and women. Specifically, the increase in the gender coefficient from -0.45 in the bivariate model to 0.30 in the second model is largely due to gendered differences in the distribution of education and caste/ethnicity. The coefficients of 0.45 for $8-11$ years of schooling and 0.55 for more than 11 years of schooling indicate that respondents with this level of education are more likely to have a positive attitude toward tiger. As seen in table 1 above, women have less education than men. Thus, once we control for education, we explain some of the gender gap in attitude toward tigers. The coefficients of -.38 for Dalit and -.60 for indigenous terai groups indicate that respondents of these castes/ethnicities have more negative attitudes toward tigers than the other castes/ethnicities. While the gender distributions do not differ significantly by caste/ethnicity, the inclusion of ethnicity in the model does explain a marginal amount of variation in gendered attitudes. Age, occupation, and residency do not have a significant effect on attitude and, thus, do not help explain the gender gap in attitude.

\section{[Table 2 about here]}

In model 3, when we add experience with tigers to the bivariate model, the gender coefficient rises to -.46 , indicating that experience with tigers increases the gap in attitudes between men and women. Examining the coefficients, we find that people are more likely to have negative attitudes toward tigers if they had seen tiger sign in the past. Women are not as likely to have seen tiger sign, thus, if they had seen sign to the same extent as men, this model suggests they would be even more negative than they are.

In model 4, when the perception of risk variables (i.e., the scaled measures of worry about risk and likelihood of risk) are added to the bivariate model (Table 2), the coefficient for gender decreases from -.45 to -.37, indicating that gendered differences in perceptions of risk explain some of the gap in attitudes. Specifically, the coefficients are -.34 for worry and -.16 for likelihood, indicating that both of these categories of perceptions are increasing the gap between women's and men's attitude. Furthermore, worry about tiger-related risks has twice the effect on attitudes than the perception of the likelihood of those risks.

In model 5, adding people's perceptions of risk control to the bivariate model, the gender coefficient is -.36, indicating that it accounts for some of the gap. Specifically, the perception that risks from tigers are avoidable has a coefficient of 0.73 , which means that if women perceived that risks from tigers were as avoidable as men did, they would have more positive attitudes toward tiger.

In model 6, adding beliefs about tigers to the bivariate model (except for religious value because it did not differ significantly by gender), the gender coefficient becomes insignificant, decreasing to -0.09. All of the belief questions are significant in this model, indicating that beliefs about tigers explain a large amount of the difference in attitude between women and men. Believing 
that tigers are a nuisance and that there is not enough room for them in the forest contribute to a more negative attitude, while the remaining belief questions contribute to a more positive attitude.

Finally, in the full model, the gender coefficient drops to -0.002 , meaning that all the variables combined account for more of the gender difference than any one set. In this model, education becomes insignificant, indicating that some other variable or variables explains the effect of education on attitude found in model 2 , and having lived in the village for less time (1-14 years) becomes significant, contributing to a more negative attitude. Believing that tigers are a nuisance becomes insignificant.

\subsection{Which socio-economic characteristics and perceptions are most influential in explaining the gendered difference in attitude?}

The difference in men's attitudes toward tigers versus women's attitudes is 0.45 units, amounting to nearly $20 \%$ of the total range of attitude scores $(-1.63-0.68)$ among all respondents (Table 3 ). The predictors in the decomposition model account for 0.43 of these units or $94.3 \%$ of this difference. Thus, very little of the gender gap in attitude remains unexplained by the full model.

[Table 3 about here]

The decomposition analysis shows that beliefs about tigers explain the majority, 0.30 units or $66.56 \%$, of the gender gap in attitude toward tiger (Table 3). The belief that tigers contribute to keeping the forest healthy by itself explains almost one third of the gap $(0.14$ units or $31 \%)$. Each of the other beliefs explains between 0.02 and 0.04 units and $4-10 \%$ of the gender gap in attitudes. All are statistically significant except for the belief that tigers are a nuisance.

All of the other groups of variables explain much less of the gap than beliefs. Socio-economic characteristics account for 0.05 units or $11.53 \%$ of the gap (Table 3). In keeping with the small overall contribution of socio-economic characteristics, the individual contributions of socioeconomic characteristics are also relatively small. Age, education, occupation, and residency length account for $0.00,0.01,0.03,0.02$ units of the gap respectively. Further, none of these contributions to explaining the gap differs significantly from zero.

Experience with tigers explains $6 \%$ of the difference in attitudes, although neither measure is significant (Table 3). Perceptions of worry and likelihood of risk combined also explain nearly $6 \%$ of the gap, with worry explaining more than $4 \%$. One of the measures of control, that risks are avoidable, explains nearly $5 \%$ of the gap.

\section{Discussion}

We found that our model explained nearly all of the gendered attitude gap toward tiger, with differences in beliefs about tigers explaining two-thirds of the gap and the other categories of variables explaining the remainder. Within the other categories, the most significant variables were perceptions of risk and control over risk, while socio-economic characteristics did not play a significant role. This supports the hypothesis that different fear levels between women and men play a role in their attitudes toward and tolerance of wildlife. Because gendered differences in fear seem to be fairly universal (Fredrikson et al. 1996; Gustafsod 1998), it may be difficult to 
reduce women's fear in order to improve their attitude, and would, regardless, contribute little to reducing the gap in attitudes.

The finding that beliefs play a more substantial role in explaining the gap between women's and men's attitude toward tigers correspond with other studies that have found that people's beliefs about protected areas are the most important drivers of attitudes (Allendorf \& Allendorf 2013; Allendorf \& Yang 2013). One belief in particular, that tigers contribute to a healthy forest, explained one-third of the gap in attitudes. Thus, in Chitwan, women are less positive toward tigers largely because they are less likely to perceive that tigers play a role in maintaining a healthy forest.

The role of belief that tigers are important to a healthy forest is similar to results from Myanmar and China where women are less likely to have positive attitudes toward protected areas primarily because they are less likely to perceive ecosystem benefits, such as better climate, more water, and better soil (Allendorf \& Allendorf 2013; Allendorf \& Yang 2015). Other studies have also found that women are less likely to perceive benefits because they have less knowledge (Moorman, 2006; Xu et al., 2006). In general, women know less than men about why protected areas were created and who created them (Allendorf and Yang, 2015; Moorman, 2006; $\mathrm{Xu}$ et al., 2006). They are less knowledgeable because they usually have less formal education and because they have less access to other sources of information, such as public meetings and community groups, due to cultural and time constraints. Interestingly, however, environmental knowledge is also gendered in developed countries, where women have less ecological knowledge (Kellert \& Berry 1987; Diamantopoulos et al. 2003).

We hypothesize that if women around CNP had as much access to information about tigers through formal education, interactions with protected area staff, and development and conservation projects as men, they would be more positive, possibly even more positive than men. We hypothesize this because, unlike women in China and Myanmar, women in Nepal are not more negative toward protected areas, despite having less knowledge (Allendorf 2007; Baral \& Heinen 2007). While gender disparities and inequities are significant in Nepal, overall trends are in positive directions (Mishra 2012) and Nepal has made efforts to include women in buffer zone projects over the past 20 or more years, including policies that recommend their representation on elected committees, which includes community forestry and buffer zone committees, both of which exist in CNP (Chhetri et al. 2008). These efforts, although arguably insufficient, have contributed to men and women being equally likely to perceive benefits from the park and the buffer zone program (Spiteri \& Nepal 2008).

These findings are important, not because women are either more "vulnerable or virtuous" than men in terms of wildlife conservation, but because they highlight potential pathways to increase community support for and involvement in wildlife conservation (Arora-Jonsson 2011). The fact that knowledge may underlie much of the difference in gendered attitudes has important implications for management. It is easier to increase people's access to information than to increase their income, for example. Thus, outreach programs targeted at women that increase their knowledge about particular species and their role in ecosystem services may significantly improve community attitudes overall. This approach may also improve attitudes of other groups that often have less access to knowledge, such as poor and marginalized communities. 
Would more positive attitudes among women directly impact tiger conservation? Women are not known to be directly involved in poaching or killing of tiger. However, women directly contribute to tiger conservation through their contribution to household decision-making and within their communities. We can describe these contributions in terms of intra-household and extra-household (Agarwal, 1997). Within households, women impact decisions that are made about livelihood and well-being strategies. For example, in one community forest group in Chitwan, the young men who were participating said they had not left to work in the Middle East because they preferred to contribute to their village's development. However, they mentioned that some of their wives pressured them to go overseas to make more income. Thus, the more support for conservation among individual members of households, we would predict that the more decisions will be made that support conservation. In terms of poaching, studies have shown that when women are actively involved in activities such as community forestry, rules are more widely known and followed (Agarwal 2009). The same may happen with laws about poaching if women's knowledge were increased, they may influence their male family members to not participate in poaching. Also, as the primary childcare givers, women can impart and reinforce knowledge and positive attitudes in their children, which has long-term implications for conservation. At the community level, the more knowledgeable and positive women are about tiger, the more they can help to ensure that tigers are protected and laws followed through collective action, such as community forest group activities, and through their activities as individuals (Doss, 2013). For example, anti-poaching informant networks are an important component of tiger conservation activities in CNP. Women, because they collect fodder and fuelwood from the park and from community forests around the park regularly to meet daily household needs, can be an important source of information about strangers in the area or local residents who might be involved in poaching.

Understanding the different roles and perspectives that women and men have concerning natural resources is important to meeting development and environment goals (Rajvanshi \& Arora 2010). While a great deal of progress has been made in understanding gendered relationships with the environment and the importance of gender to environmental issues (Arora-Jonsson 2014), wildlife in all aspects (research, management, hunting) is still very male-centered, not only in developing countries like Nepal, but also in the United States (Kern et al., 2015; Nicholson et al., 2008) and Europe (Heberlein et al., 2008; Svarstad et al., 2006). More awareness of gendered perspectives of wildlife will contribute to better management and conservation. It will provide much-needed insights on how to facilitate human adaptation to wildlife, which is key to human-wildlife coexistence (Carter and Linnell, 2016).

\section{Acknowledgements}

We acknowledge our colleagues in the Institute for Social and Environmental Research-Nepal in Chitwan for their contributions to this article. We thank Keera Allendorf for her critical contribution and advice. We also thank three anonymous reviewers for their helpful comments. Research was supported by the U.S. Fish and Wildlife Service Rhinoceros and Tiger Conservation Fund, Michigan State University's Partnership for Ecosystem Research and Management, Boise State University (NSF award number IIA-1301792 from the NSF Idaho EPSCoR Program and the National Science Foundation), and NASA's Earth and Space Science program. 


\section{References}

Agarwal, B., 2009. Gender and forest conservation: The impact of women's participation in community forest governance. Ecol. Econ. 68, 2785-2799. doi:10.1016/j.ecolecon.2009.04.025

Agarwal, B., 2000. Conceptualising environmental collective action: why gender matters. Camb. J. Econ. 24, 283-310.

Agarwal, B., 1997. Bargaining', and Gender Relations: Within and Beyond the Household. Fem. Econ. 3, 1-51.

Allendorf, T.D., 2007. Residents' attitudes toward three protected areas in southwestern Nepal. Biodivers. Conserv. 16, 2087-2102.

Allendorf, T.D., Allendorf, K., 2013. Gender and attitudes toward protected areas in Myanmar. Soc. Nat. Resour. 26, 962-976. doi:10.1080/08941920.2012.729295

Allendorf, T.D., Yang, J., 2013. The role of ecosystem services in park-people relationships: The case of Gaoligongshan Nature Reserve in southwest China. Biol. Conserv. 167, 187193. doi:10.1016/j.biocon.2013.08.013

Allendorf, T.D., Yang, J.M., 2015. The role of gender in local residents' relationships with Gaoligongshan Nature Reserve, Yunnan, China. Environ. Dev. Sustain. 1-14. doi:10.1007/s10668-015-9731-1

Arjunan, M., Holmes, C., Puyravaud, J.P., Davidar, P., 2006. Do developmental initiatives influence local attitudes toward conservation? A case study from the KalakadMundanthurai Tiger Reserve, India. J. Environ. Manage. 79, 188-197.

Arora-Jonsson, S., 2014. Forty years of gender research and environmental policy: Where do we stand? Womens Stud. Int. Forum, Special Issue on Gender, Mobility and Social Change Guest Edited by Lena Nare and Parveen Akhtar 47, Part B, 295-308. doi:10.1016/j.wsif.2014.02.009

Arora-Jonsson, S., 2011. Virtue and vulnerability: Discourses on women, gender and climate change. Glob. Environ. Change, Special Issue on The Politics and Policy of Carbon Capture and Storage 21, 744-751. doi:10.1016/j.gloenvcha.2011.01.005

Baral, N., Heinen, J.T., 2007. Resources use, conservation attitudes, management intervention and park-people relations in the Western Terai landscape of Nepal. Environ. Conserv. 34, 64-72.

Bearer, S., Linderman, M., Huang, J., An, L., He, G., Liu, J., 2008. Effects of fuelwood collection and timber harvesting on giant panda habitat use. Biol. Conserv. 141, 385-393.

Bjerke, T., Vitterso, J., Kaltenborn, B.P., 2000. Locus of control and attitudes toward large carnivores. Psychol. Rep. 86, 37-46.

Blinder, A.S., 1973. Wage Discrimination: Reduced Form and Structural Estimates. J. Hum. Resour. 8, 436-455. doi:10.2307/144855

Bohra, P., Massey, D.S., 2009. Processes of internal and international migration from Chitwan, Nepal. Int. Migr. Rev. 43, 621-651.

Bruskotter, J.T., Wilson, R.S., 2014. Determining where the wild things will be: Using psychological theory to find tolerance for large carnivores. Conserv. Lett. 7, 158-165. doi: $10.1111 /$ conl.12072

Carter, N., Linnell, J.D.C., 2016. Co-adaptation is key to coexisting with large carnivores. Trends Ecol. Evol. DOI: http://dx.doi.org/10.1016/j.tree.2016.05.006.

Carter, N.H., Riley, S.J., Liu, J., 2012a. Utility of a psychological framework for carnivore conservation. Oryx 46, 525-535. doi:10.1017/S0030605312000245 
Carter, N.H., Riley, S.J., Shortridge, A., Shrestha, B.K., Liu, J., 2014a. Spatial Assessment of Attitudes Toward Tigers in Nepal. AMBIO 43, 125-137. doi:10.1007/s13280-013-04217

Carter, N.H., Shrestha, B.K., Karki, J.B., Pradhan, N.M.B., Liu, J., 2012b. Coexistence between wildlife and humans at fine spatial scales. Proc. Natl. Acad. Sci. 109, 15360-15365.

Carter, N.H., Viña, A., Hull, V., McConnell, W.J., Axinn, W., Ghimire, D., Liu, J., 2014b. Coupled human and natural systems approach to wildlife research and conservation. Ecol. Soc. 19. doi:10.5751/ES-06881-190343

CBS, 2012. Central Bureau of Statistics, National Planning Commission Secretariat, Government of Nepal. http://cbs.gov.np/.

Chen, X., Frank, K.A., Dietz, T., Liu, J., 2012. Weak ties, labor migration, and environmental impacts toward a sociology of sustainability. Organ. Environ. 25, 3-24.

Chhetri, R.B., Timsina, N.P., Luintel, H., Regmi, R., Bhattarai, B., Magar, R.A., Sannyashi, N., Sharma, G., Sijapati, D., Sharma, P., 2008. Decentralization and Promotion of Women's Rights in Nepal: Exploring Constraints, Opportunities and Intervention Avenues. IDRC.

Colfer, C.J.P., 2013. The gender box: A framework for analysing gender roles in forest management. CIFOR.

Czech, B., Devers, P.K., Krausman, P.R., 2001. The relationship of gender to species conservation attitudes. Wildl. Soc. Bull. 29, 187-194.

Dhungana, R., Savini, T., Karki, J.B., Bumrungsri, S., 2016. Mitigating human-tiger conflict: an assessment of compensation payments and tiger removals in Chitwan National Park, Nepal. Trop. Conserv. Sci. 9, 776-787.

Diamantopoulos, A., Schlegelmilch, B.B., Sinkovics, R.R., Bohlen, G.M., 2003. Can sociodemographics still play a role in profiling green consumers? A review of the evidence and an empirical investigation. J. Bus. Res. 56, 465-480. doi:10.1016/S01482963(01)00241-7

Dorius, S.F., Firebaugh, G., 2010. Trends in global gender inequality. Soc. Forces 88, 19411968. doi:10.1353/sof.2010.0040

Doss, C., 2013. Intrahousehold Bargaining and Resource Allocation in Developing Countries. World Bank Res. Obs. 28, 52-78. doi:10.1093/wbro/lkt001

Dougherty, E.M., Fulton, D.C., Anderson, D.H., 2003. The influence of gender on the relationship between wildlife value orientations, beliefs, and the acceptability of lethal deer control in Cuyahoga Valley National Park. Soc. Nat. Resour. 16, 603-623.

Fredrikson, M., Annas, P., Fischer, Hå., Wik, G., 1996. Gender and age differences in the prevalence of specific fears and phobias. Behav. Res. Ther. 34, 33-39. doi:10.1016/00057967(95)00048-3

Gillingham, S., Lee, P.C., 1999. The impact of wildlife-related benefits on the conservation attitudes of local people around the Selous Game Reserve, Tanzania. Environ. Conserv. 26, 218-228.

Gore, M.L., Kahler, J.S., 2012. Gendered risk perceptions associated with human-wildlife conflict: implications for participatory conservation. PLoS ONE 7, e32901. doi:10.1371/journal.pone.0032901

Government of Nepal, 1993. Fourth amendment to the national parks and wildlife conservation act (2029). Nepal Gazette, 43 (Suppl.).

Grant, M.J., Behrman, J.R., 2010. Gender gaps in educational attainment in less developed countries. Popul. Dev. Rev. 36, 71-89. doi:10.1111/j.1728-4457.2010.00318.x 
Gurung, B., Smith, J.L.D., McDougal, C., Karki, J.B., Barlow, A., 2008. Factors associated with human-killing tigers in Chitwan National Park, Nepal. Biol. Conserv. 141, 3069-3078.

Gustafsod, P.E., 1998. Gender differences in risk perception: Theoretical and methodological perspectives. Risk Anal. 18, 805-811.

Heberlein, T.A., Serup, B., Ericsson, G., 2008. Female hunting participation in North America and Europe. Hum. Dimens. Wildl. 13, 443-458. doi:10.1080/10871200802294265

Hill, C.M., 1998. Conflicting attitudes towards elephants around the Budongo Forest Reserve, Uganda. Environ. Conserv. 25, 244-250.

Hogberg, J., Treves, A., Shaw, B., Naughton-Treves, L., 2015. Changes in attitudes toward wolves before and after an inaugural public hunting and trapping season: early evidence from Wisconsin's wolf range. Environ. Conserv. 1-11. doi:10.1017/S037689291500017X

Hunter, M.L., Hitchcock, R.K., Wyckoff-Baird, B., 1990. Women and wildlife in Southern Africa. Conserv. Biol. 4, 448-451.

Jann, B., 2008. The Blinder-Oaxaca decomposition for linear regression models. Stata J. 8, 453479. doi:The Stata Journal

Kaltenborn, B.P., Bjerke, T., Nyahongo, J., 2006a. Living with problem animals-self-reported fear of potentially dangerous species in the Serengeti region, Tanzania. Hum. Dimens. Wildl. 11, 397-409. doi:10.1080/10871200600984323

Kaltenborn, B.P., Bjerke, T., Nyahongo, J., 2006b. Living with Problem Animals-SelfReported Fear of Potentially Dangerous Species in the Serengeti Region, Tanzania. Hum. Dimens. Wildl. 11, 397-409. doi:10.1080/10871200600984323

Kansky, R., Kidd, M., Knight, A.T., 2014. Meta-analysis of attitudes toward damage-causing mammalian wildlife. Conserv. Biol. 28, 924-938. doi:10.1111/cobi.12275

Karki, J.B., Pandav, B., Jnawali, S.R., Shrestha, R., Pradhan, N.M.B., Lamichane, B.R., Khanal, P., Subedi, N., Jhala, Y. V, 2015. Estimating the abundance of Nepal's largest population of tigers Panthera tigris. Oryx 49, 150-156.

Kellert, S.R., Berry, J.K., 1987. Attitudes, knowledge, and behaviors toward wildlife as affected by gender. Wildl. Soc. Bull. 15, 363-371.

Kern, C.C., Kenefic, L.S., Stout, S.L., 2015. Bridging the gender gap: The demographics of scientists in the USDA Forest Service and academia. BioScience biv144. doi:10.1093/biosci/biv144

Laurie, A., 1982. Behavioural ecology of the greater one horned rhinoceros (Rhinoceros unicornis). J. Zool. 196, 307-341.

Mishra, M.K., 2012. A comparative analysis of gender related development index and gender empowerment measures of Nepal. Glob. J. Hum.-Soc. Sci. Res. 12.

Moorman, R.S., 2006. Benefits of local residents visiting La Selva Biological Station, Costa Rica. Environ. Conserv. 33, 89-99. doi:10.1017/S0376892906002955

Neumark, D., 1988. Employers' discriminatory behavior and the estimation of wage discrimination. J. Hum. Resour. 23, 279-295.

Nicholson, K.L., Krausman, P.R., Merkle, J.A., 2008. Hypatia and the Leopold standard: Women in the wildlife profession 1937-2006. Wildl. Biol. Pract. 4. doi:10.2461/wbp.2008.4.6

Nowell, K., 2012. Wildlife Crime Scorecard: Assessing compliance with and enforcement of CITES commitments for tigers, rhinos and elephants. Switz. World Wildl. Fund 75, 11937. 
Nyaupane, G.P., Poudel, S., 2011. Linkages among biodiversity, livelihood, and tourism. Ann. Tour. Res. 38, 1344-1366. doi:10.1016/j.annals.2011.03.006

Oaxaca, R., 1973. Male-female wage differentials in urban labor markets. Int. Econ. Rev. 14, 693-709. doi:10.2307/2525981

Ogra, M. V., 2008. Human-wildlife conflict and gender in protected area borderlands: A case study of costs, perceptions, and vulnerabilities from Uttarakhand (Uttaranchal), India. Geoforum 39, 1408-1422.

Rajvanshi, A., Arora, R., 2010. Mainstreaming biodiversity and gender in impact assessment for human well-being. Biodiversity 11, 25-30. doi:10.1080/14888386.2010.9712643

Riley, S.J., Decker, D.J., 2000. Risk perception as a factor in wildlife stakeholder acceptance capacity for cougars in Montana. Hum. Dimens. Wildl. 5, 50-62.

Sharma, U.R., 1990. An overview of park-people interactions in Royal Chitwan National Park, Nepal. Landsc. Urban Plan. 19, 133-144.

Smith, J.L.D., Ahearn, S.C., McDougal, C., 1998. Landscape analysis of tiger distribution and habitat quality in Nepal. Conserv. Biol. 12, 1338-1346.

Sodhi, N.S., Davidar, P., Rao, M., 2010. Empowering women facilitates conservation. Biol. Conserv. 143, 1035-1036. doi:10.1016/j.biocon.2010.02.014

Spiteri, A., Nepal, S.K., 2008. Distributing conservation incentives in the buffer zone of Chitwan National Park, Nepal. Environ. Conserv. 35, 76-86. doi:10.1017/S0376892908004451

Suryawanshi, K.R., Bhatia, S., Bhatnagar, Y.V., Redpath, S., Mishra, C., 2014. Multiscale factors affecting human attitudes toward snow leopards and wolves. Conserv. Biol. 28, 1657-1666. doi:10.1111/cobi.12320

Svarstad, H., Daugstad, K., Vistad, O.I., Guldvik, I., 2006. New protected areas in Norway: local participation without gender equality. Mt. Res. Dev. 26, 48-54. doi:10.1659/02764741(2006)026[0048:NPAINL]2.0.CO;2

UNEP/WCMC, 2011. United Nations Environment Programme/ World Conservation Monitoring Centre - Royal Chitwan National Park, Nepal. Accessed October 10, 2014 [WWW Document]. URL http://www.unep-wcmc.org/medialibrary/2011/06/13/e26c7182/Royal Chitwan.pdf

Wikramanayake, E., Dinerstein, E., Seidensticker, J., Lumpkin, S., Pandav, B., Shrestha, M., Mishra, H., Ballou, J., Johnsingh, A.J.T., Chestin, I., 2011. A landscape based conservation strategy to double the wild tiger population. Conserv. Lett. 4, 219-227.

Xu, J., Chen, L., Lu, Y., Fu, B., 2006. Local people's perceptions as decision support for protected area management in Wolong Biosphere Reserve, China. J. Environ. Manage. 78, 362-372. doi:10.1016/j.jenvman.2005.05.003

Yang, N., Zhang, E., Chen, M., 2010. Attitudes towards wild animal conservation: a comparative study of the Yi and Mosuo in China. Int. J. Biodivers. Sci. Ecosyst. Serv. Manag. 6, 6167.

Zinn, H.C., Pierce, C.L., 2002. Values, gender, and concern about potentially dangerous wildlife. Environ. Behav. 34, 239-256. 
Figure 1. Location of the study site in Chitwan. The shaded area on the inset indicates the location of Chitwan district in Nepal. 
Table 1. Descriptive statistics with p-values from chi square tests of whether the distributions differ significantly between men and women.

\begin{tabular}{|c|c|c|c|c|}
\hline & $\begin{array}{c}\text { Men } \\
(\mathrm{n}=183) \\
\%\end{array}$ & $\begin{array}{c}\text { Women } \\
(\mathrm{n}=316) \\
\%\end{array}$ & $\begin{array}{c}\text { All } \\
(\mathrm{n}=499) \\
\%\end{array}$ & $\begin{array}{l}\text { p-value from } \\
\text { Pearson chi- } \\
\text { square test }\end{array}$ \\
\hline \multicolumn{5}{|l|}{ Socioeconomic characteristics } \\
\hline Age & & & & .68 \\
\hline$<30$ & 44 & 44 & 44 & \\
\hline $30-39$ & 20 & 24 & 22 & \\
\hline $40-49$ & 17 & 16 & 16 & \\
\hline$>49$ & 19 & 16 & 17 & \\
\hline Occupation & & & & .00 \\
\hline Other & 46 & 19 & 28 & \\
\hline Farmer & 54 & 81 & 70 & \\
\hline Education & & & & .00 \\
\hline $0-3$ & 22 & 44 & 36 & \\
\hline $4-7$ & 24 & 23 & 23 & \\
\hline $8-11$ & 38 & 25 & 30 & \\
\hline$>11$ & 16 & 8 & 11 & \\
\hline Caste/ethnicity & & & & .30 \\
\hline Chetri or Bahun & 55 & 60 & 58 & \\
\hline Indigenous hill groups & 16 & 11 & 13 & \\
\hline Dalit & 12 & 14 & 13 & \\
\hline Indigenous terai groups & 17 & 15 & 16 & \\
\hline Residency & & & & .00 \\
\hline Native & 67 & 33 & 45 & \\
\hline $1-14$ years & 12 & 36 & 27 & \\
\hline $15-29$ years & 7 & 18 & 14 & \\
\hline$>29$ years & 14 & 14 & 14 & \\
\hline \multicolumn{5}{|l|}{ Forest dependence } \\
\hline $\begin{array}{l}\text { Since last year till now, out of } 365 \text { days, } \\
\text { approximately how many work days did you spend } \\
\text { in the nearby forest collecting fodder or firewood? }\end{array}$ & & & & .47 \\
\hline 0 days & 48 & 41 & 44 & \\
\hline $1-25$ days & 31 & 35 & 34 & \\
\hline 26-50 days & 6 & 6 & 6 & \\
\hline 51-100 days & 7 & 6 & 6 & \\
\hline$>100$ days & 8 & 12 & 10 & \\
\hline \multicolumn{5}{|l|}{ Experience with tiger } \\
\hline $\begin{array}{l}\text { Have you ever seen evidence (e.g., pugmark and/or } \\
\text { scat) of tiger in Chitwan? (Yes) }\end{array}$ & 78 & 62 & 68 & .00 \\
\hline Have you ever seen a tiger in the wild? (Yes) & 55 & 36 & 43 & .00 \\
\hline \multicolumn{5}{|l|}{ Perceptions of risk } \\
\hline \multicolumn{5}{|l|}{ Worry about risk } \\
\hline $\begin{array}{l}\text { How worried are you about tigers from the nearby } \\
\text { forests will attack your farm animals? }\end{array}$ & & & & .00 \\
\hline Not worried & 25 & 24 & 24 & \\
\hline Somewhat worried & 44 & 30 & 35 & \\
\hline Very worried & 32 & 46 & 40 & \\
\hline $\begin{array}{l}\text { How worried are you about tigers from the nearby } \\
\text { forests will attack someone in your village? }\end{array}$ & & & & .03 \\
\hline
\end{tabular}


Not worried

Somewhat worried

Very worried

How worried are you about tigers from the nearby

forests will attack me or someone in your family?

Not worried

Somewhat worried

$27 \quad 30$

Very worried

Likelihood of risk

Tiger will attack my farm animals

Not likely

A little likely

Very likely

$\begin{array}{lll}5 & 10 & 8\end{array}$

$\begin{array}{lll}45 & 29 & 35\end{array}$

$\begin{array}{lll}50 & 61 \quad 57\end{array}$

Tiger will attack someone in my village

Not likely

A little likely

Very likely

$43 \quad 26 \quad 32$

$50 \quad 66 \quad 60$

Tiger will attack me or someone in my family Not likely

A little likely

Very likely

$\begin{array}{lll}8 & 9 & 9\end{array}$

$45 \quad 30 \quad 36$

$\begin{array}{lll}46 & 60 & 55\end{array}$

\section{Control over risk}

Are risks from tigers avoidable? (Yes)

Are the risks from tigers in Chitwan understood by the government or government officials? (Yes)

Beliefs about tiger

Do you agree that Tigers are a nuisance and should be kept out of the nearby forests at all costs? (Yes)

Do you agree that there is not enough room for both tigers and humans to live in Chitwan so tigers should leave the nearby forests? (Yes)

Do you agree that your village will benefit from more tourism if tigers are in the nearby forests? (Yes)

Do you agree that tigers should stay in the nearby forests because they keep the forests healthy? (Yes) Do you agree that tigers are an important part of your culture and should continue roaming the nearby forests? (Yes)

Do you agree that tigers were in Chitwan before humans and have the right to live in the nearby forests alongside humans? (Yes)

\section{Attitude toward tigers}

Does it please you just knowing that tigers exist in the nearby forests? (Yes)

$\begin{array}{llll}83 & 71 & 75 & .00 \\ 83 & 64 & 71 & .00 \\ 19 & 45 & 35 & .00\end{array}$


Table 2. Results from generalized linear model of attitude toward tigers $(n=499)$.

\begin{tabular}{|c|c|c|c|c|c|c|c|}
\hline & $\begin{array}{l}\text { Model 1: } \\
\text { Bivariate }\end{array}$ & $\begin{array}{l}\text { Model 2: Socio- } \\
\text { economic } \\
\text { characteristics }\end{array}$ & $\begin{array}{c}\text { Model 3: } \\
\text { Experience with } \\
\text { tiger }\end{array}$ & $\begin{array}{c}\text { Model 4: } \\
\text { Perceptions of } \\
\text { risk }\end{array}$ & $\begin{array}{l}\text { Model 5: } \\
\text { Perceptions of } \\
\text { risk control }\end{array}$ & $\begin{array}{l}\text { Model 6: Beliefs } \\
\text { about tiger }\end{array}$ & $\begin{array}{l}\text { Model 7: } \\
\text { Full }\end{array}$ \\
\hline $\begin{array}{l}\text { Respondent is a } \\
\text { woman }\end{array}$ & $-0.45 * *$ & $-0.30 * *$ & $-0.46 * *$ & $-0.37 * *$ & $-0.36 * *$ & -0.09 & 0.00 \\
\hline \multicolumn{8}{|l|}{ Age } \\
\hline$<30$ (ref) & & 0.00 & & & & & 0.00 \\
\hline $30-39$ & & -0.02 & & & & & -0.05 \\
\hline $40-49$ & & 0.17 & & & & & 0.05 \\
\hline$>49$ & & -0.16 & & & & & -0.13 \\
\hline \multicolumn{8}{|l|}{ Occupation } \\
\hline Other (ref) & & 0.00 & & & & & 0.00 \\
\hline Farmer & & -0.16 & & & & & -0.10 \\
\hline \multicolumn{8}{|l|}{ Education } \\
\hline $0-3$ (ref) & & 0.00 & & & & & 0.00 \\
\hline $4-7$ & & 0.04 & & & & & 0.08 \\
\hline $8-11$ & & $0.45^{* *}$ & & & & & 0.08 \\
\hline$>11$ & & $0.55 * *$ & & & & & 0.08 \\
\hline \multicolumn{8}{|l|}{ Ethnicity } \\
\hline Chetri or Bahun & & 0.00 & & & & & 0.00 \\
\hline $\begin{array}{l}\text { Indigenous hill } \\
\text { groups }\end{array}$ & & 0.10 & & & & & 0.10 \\
\hline Dalit & & $-0.38 * *$ & & & & & $-0.26 * *$ \\
\hline $\begin{array}{l}\text { Indigenous terai } \\
\text { groups }\end{array}$ & & $-0.60 * *$ & & & & & $-0.39 * *$ \\
\hline \multicolumn{8}{|l|}{ Residency } \\
\hline Native (ref) & & 0.00 & & & & & 0.00 \\
\hline 1-14 years & & -0.10 & & & & & $-0.16^{*}$ \\
\hline $15-29$ years & & 0.12 & & & & & -0.04 \\
\hline$>29$ years & & 0.03 & & & & & -0.15 \\
\hline \multicolumn{8}{|l|}{ Experience with tiger } \\
\hline seen tiger sign & & & $-0.22 *$ & & & & 0.03 \\
\hline seen tiger & & & 0.14 & & & & 0.08 \\
\hline \multicolumn{8}{|l|}{ Perceptions of risk } \\
\hline $\begin{array}{l}\text { Worry about risk } \\
\text { (scale) }\end{array}$ & & & & $-0.34 * *$ & & & $-0.09^{* * *}$ \\
\hline
\end{tabular}




\begin{tabular}{|c|c|c|c|c|c|c|c|}
\hline $\begin{array}{l}\text { Likelihood of risk } \\
\text { (scale) }\end{array}$ & & & & $-0.16^{* *}$ & & & $-0.06^{*}$ \\
\hline \multicolumn{8}{|l|}{ Control over risk } \\
\hline Risks avoidable & & & & & $0.73 * *$ & & $0.17 * *$ \\
\hline $\begin{array}{l}\text { Risks understood } \\
\text { by government }\end{array}$ & & & & & -.05 & & 0.02 \\
\hline \multicolumn{8}{|l|}{ Beliefs about tiger } \\
\hline Nuisance & & & & & & $-0.27 * *$ & -0.11 \\
\hline Not enough room & & & & & & $-0.16^{*}$ & $-0.16^{*}$ \\
\hline Tourism benefits & & & & & & $0.49 * *$ & $0.44 * *$ \\
\hline Healthy forest & & & & & & $0.74 * *$ & $0.65 * *$ \\
\hline Part of culture & & & & & & $0.30 * *$ & $0.26 * *$ \\
\hline Right to live & & & & & & $0.32 * *$ & $0.25 *$ \\
\hline Log likelihood & -632.28 & -575.85 & -628.04 & -585.59 & -597.11 & -464.05 & -418.52 \\
\hline Model $\chi^{2}$ & 385.15 & 306.05 & 379.71 & 318.63 & 334.16 & 192.82 & 159.75 \\
\hline AIC & 1270.57 & 1183.69 & 1266.7 & 1181.19 & 1204.22 & 946.10 & 893.04 \\
\hline
\end{tabular}


Table 3. Decomposition of the difference between men's and women's attitudes toward tiger.

\begin{tabular}{lccc}
\hline & $\begin{array}{c}\text { Attitude } \\
\text { units }\end{array}$ & $\begin{array}{c}\text { Percentage } \\
\text { explained }\end{array}$ & p-value \\
\hline Difference (M-W) & 0.45 & 100.00 & \\
Explained & 0.43 & 94.34 & \\
Unexplained & 0.02 & 5.66 & \\
& & & \\
Detailed Contributions: & & & \\
& & & \\
Characteristics (sum) & $\mathbf{0 . 0 5}$ & $\mathbf{1 1 . 5 3}$ & \\
Age & 0.00 & -0.30 & 0.66 \\
Ethnicity & -0.01 & -1.94 & 0.00 \\
Education & 0.01 & 2.23 & 0.62 \\
Farmer & 0.03 & 6.30 & 0.13 \\
Residency length & 0.02 & 5.24 & 0.10 \\
Experience (sum) & $\mathbf{0 . 0 3}$ & $\mathbf{6 . 0 4}$ & \\
Seen tiger sign & 0.01 & 2.23 & 0.33 \\
Seen tiger & 0.02 & 3.80 & 0.14 \\
Perceptions of risk (sum) & $\mathbf{0 . 0 3}$ & $\mathbf{5 . 8 2}$ & \\
Worry & 0.02 & 4.06 & 0.00 \\
$\quad$ Likelihood & 0.01 & 1.77 & 0.04 \\
Control (sum) & $\mathbf{0 . 0 2}$ & $\mathbf{4 . 3 9}$ & \\
Risks avoidable & 0.02 & 4.95 & 0.01 \\
Risks understood by & & & \\
government & 0.00 & -0.56 & 0.74 \\
Beliefs about tigers (sum) & $\mathbf{0 . 3 0}$ & $\mathbf{6 6 . 5 6}$ & \\
$\quad$ Nuisance & 0.02 & 5.20 & 0.11 \\
Not enough room & 0.03 & 6.90 & 0.06 \\
Tourism benefits & 0.04 & 9.75 & 0.00 \\
Keep forests healthy & 0.14 & 30.87 & 0.00 \\
Part of culture & 0.04 & 9.75 & 0.00 \\
Right to live & 0.02 & 4.09 & 0.04 \\
\hline
\end{tabular}




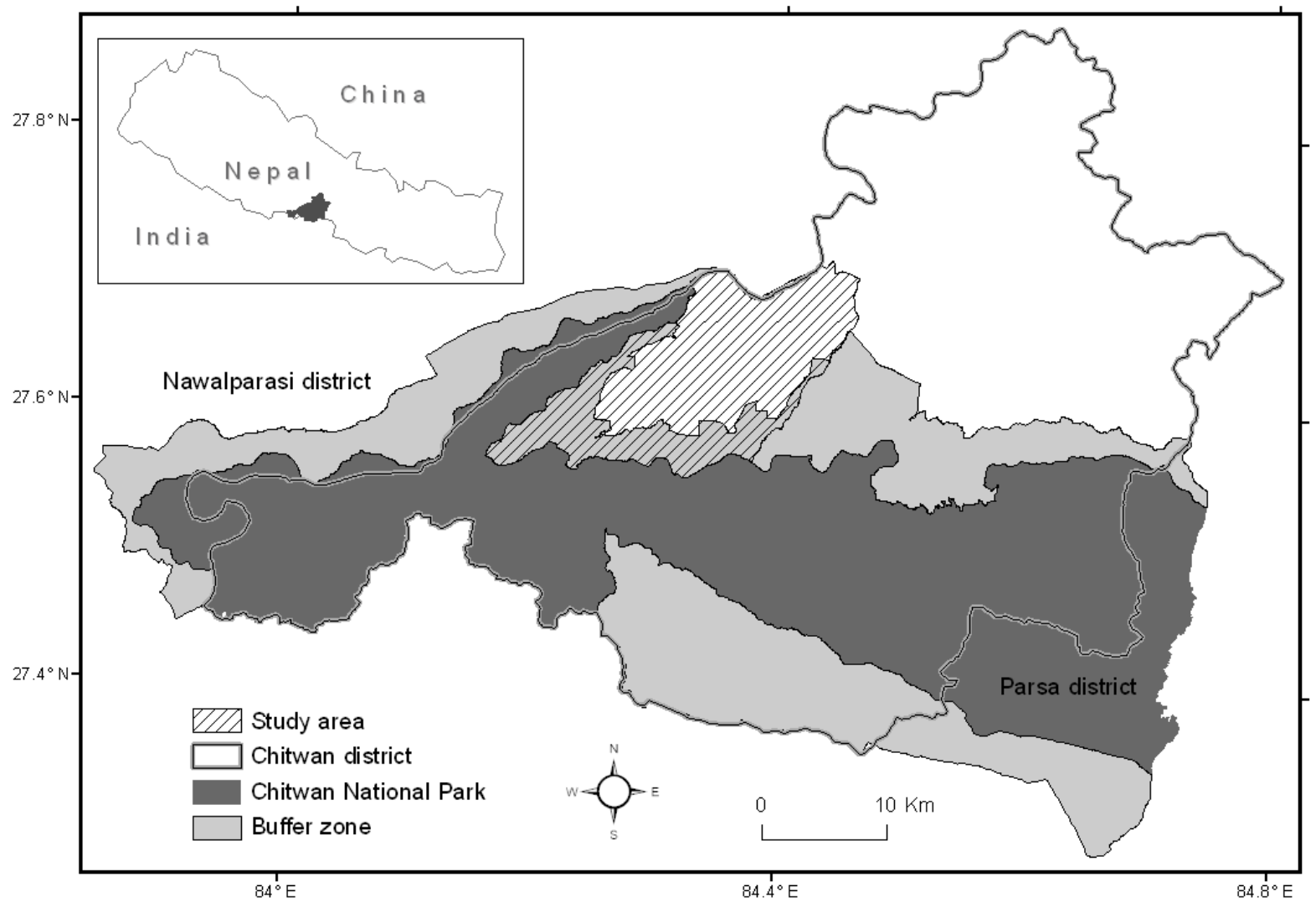

